\title{
Comparison of diet history interview and self completed questionnaire in assessment of diet in an elderly population
}

\author{
Nicola Jackson, Julian Little, Andrew D Wilson
}

\section{Abstract}

Study objective-The aim of the study was to determine the reliability of a diet history interview with a short self completed questionnaire of a basic design used in other studies in the United Kingdom.

Design-The study used a cohort of elderly people randomly divided into two groups after stratification for sex. Members of one group completed the questionnaire first and were interviewed later; the procedure was reversed for the other group.

Setting-Participants were drawn from registers of two general practitioners at a Nottingham health centre.

Participants-All non-Asian men aged 65-74 years and women aged 59-65 years registered with the practices were identified $(n=152) ; 20$ could not be traced and two were too ill, leaving 130 possible participants. Of these, 80 took part in the study.

Measurements and results-Ranking of subjects in terms of estimated fat, fibre, and calcium intakes was compared in the history interview and in the self completed questionnaire. Agreement in tertile ranking was $58 \%$ for fibre, $53 \%$ for fat, and $49 \%$ for calcium. Corresponding correlation coefficients for estimated nutrient intakes were $0.49,0.45$, and 0.41 respectively. The differences in nutrient intakes estimated by the two methods were not affected by age, sex, marital status, or smoking patterns. Subjects in the group asked to complete the questionnaire before being interviewed showed greater percentage concordance for tertile ranking, but this reached significance only for fat intake.

Conclusions-The two methods provide estimates of intakes similar to those found in other studies in the United Kingdom, and the agreement between them in terms of tertile ranking is also similar to previous studies. The incidence of gross misclassification was low.

Increasing attention to the role of diet in the aetiology of chronic disease has motivated attempts to collect quantitative dietary data in large scale cohort and case-control studies. The available methods of collecting such data are of four broad types: (1) dietary diaries, with or without direct weighing; (2) interval recall methods; (3) tissue sample assays; (4) food frequency interviews or questionnaires, with or without an assessment of habitual portion sizes. ${ }^{12}$ In the first approach, the possibility cannot be excluded that subjects may change their diet during the survey period, and a high degree of commitment is required on the part of subjects which may affect the participation rate. ${ }^{3}$ Despite these difficulties, the seven day weighed record has frequently been used as a reference method with which to compare other methods of dietary assessment. Interval recall methods are of limited value because the dietary intake during the recalled period, typically between 24 hours and seven days, may not be representative of habitual diet. ${ }^{14}$ In the approach based on tissue sample assays, participation rates may be poor, the assays may be relatively expensive, and the approach is appropriate only for a limited range of nutrients. $^{56}$ By contrast, while the fourth approach does not allow precise estimation of nutrient intakes, it has been shown to enable subjects to be ranked in terms of their reported intakes of specific nutrients consistently. ${ }^{1}$

A case-control study of diet and asymptomatic colorectal adenomatous polyps has been in progress in Nottingham since 1985. As the subjects were recruited through a trial of faecal occult blood screening for colorectal cancer, ${ }^{7}$ we were concerned that the method of data collection should not affect their compliance with the trial protocol and should not raise anxieties. In addition, we sought to obtain information on potential confounding variables such as occupational and leisure activity, and to obtain faecal samples. For these reasons, we opted to interview subjects in their homes after all investigations and treatment had been completed, and this decision led us to collect the dietary data by the diet history interview approach. The dietary section of the interview schedule was based on that originally planned for the European Organisation for Cooperation in Cancer Prevention (ECP) case-control study of symptomatic adenomatous polyps and cancer of the large bowel, in order to facilitate comparison between the studies. Data obtained using the schedule on which that of the ECP was to be based had been compared with data obtained from seven day weighed records in a sample of volunteers of all ages in Paris, and in a sample of elderly women living on their own in another area of France. ${ }^{8} \mathrm{Fat}$ intake as estimated from the diet history method was lower than that estimated from weighed records, but estimated intakes of other nutrients were similar. Accordingly, the schedule was modified to include specific questions about fats consumed in, or used in the preparation of, a substantial proportion of meals. Certain other modifications were made to render the schedule appropriate for use in the United Kingdom. There was a need to investigate the reliability of 
the modified schedule. We did this in two ways. First, we carried out repeat interviews on a subset of subjects in the case-control study; the results of the repeat interviews will be reported later. Second, we compared data obtained from the diet history section of the interview schedule used in the Nottingham study of colorectal adenomatous polyps with data obtained from a short self completed questionnaire which has been used in other studies in the United Kingdom, and found to give estimates of nutrient intakes moderately highly $(r \geqslant 0.5)$ correlated with weighed records. ${ }^{9}$ The present paper is a report on the results of this investigation.

The study was carried out on elderly subjects. Such subjects are at risk of chronic diseases in which a dietary aetiology is suspected. Intakes of fibre, fat and calcium were considered in the present study because of widespread interest in their possible role in the aetiology of colorectal cancer. ${ }^{10-15}$

In recent reports, questionnaires in which frequency of intake alone has been assessed have been used to estimate nutrient intake. However, many authors contradict one another as to the adequacy of this approach. For example, Hunt ${ }^{16}$ concluded that food frequency questionnaires were poor in determining long term intake. Their use was of value, however, in the early clue seeking stages of a study when more expensive methods cannot be justified. Block ${ }^{17}$ contradicted this view and reported that in a number of studies, intakes estimated from brief food frequency interviews or questionnaires have been found to have high correlations with those obtained from more extensive diet histories. The results of the present study also contribute to this debate.

The study was carried out in an area of inner city deprivation, the area with the second highest "disadvantage score" (based on the indicators of low income, unemployment, lack of skills, poor housing, poor health, family problems and educational problems) in Nottinghamshire. ${ }^{18}$ In view of the recent interest in the associations between diet and inequality in health, ${ }^{19} 20$ it is important to investigate the utility of methods of dietary assessment in areas of deprivation.

\section{Methods}

All men aged 65-74 years and women aged 59-69 were identified from the age-sex registers of two General Practitioners at a local health centre. All subjects with Asian surnames were excluded from the study. This method of name identification has

Table I Summary of study procedures

\begin{tabular}{|c|c|c|}
\hline & Group 1 & Group 2 \\
\hline Mid-August 1987 & $\begin{array}{l}\text { Recruitment letter } \\
\text { Self completed questionnaire } \\
\text { Reply paid card }\end{array}$ & \\
\hline Early September 1987 & $\begin{array}{l}\text { Interviews arranged by } \\
\text { telephone or personal visit }\end{array}$ & $\begin{array}{l}\text { Recruitment letter } \\
\text { Reply paid card }\end{array}$ \\
\hline Mid-September 1987 & Reminder letters & $\begin{array}{l}\text { Interviews arranged by } \\
\text { telephone or personal visit }\end{array}$ \\
\hline Late September 1987 & & $\begin{array}{l}\text { Self completed questionnaires } \\
\text { sent after interview } \\
\text { Reminder letters }\end{array}$ \\
\hline Mid-October 1987 & End of data collection & \\
\hline
\end{tabular}

been shown to be highly reliable. ${ }^{21}$ Asians were omitted because of possible language difficulties, which, together with the different diets they follow, would have complicated the questionnaire design, and because the epidemiology of chronic diseases in Asians appears to differ from that of the UK population. ${ }^{22} 23$

Out of a total of 169 subjects, 20 had addresses missing on the age-sex register or could not be found in the general practitioner record files, and 17 were Asian. Two men were thought by the GP to be too ill to take part in the study, or were in hospital. This left a total of 130 subjects whose participation could be sought. Participation was originally sought by letter. Respondents were asked to return a reply paid card indicating whether they were willing to take part.

As it was possible that the order in which the interview and questionnaire were completed might affect the results, the study population was randomly divided into two groups after stratification for sex. Members of one group (group 1) were asked to complete the questionnaire first and the interview was carried out later. The reverse procedure was followed for the second group (group 2). The recruitment procedure is summarised in table $I$.

In both the interview and questionnaire, the aim was to estimate the weekly dietary intakes of fibre, fat and calcium over the previous 12 months. The diet history interview was abstracted from the interview schedule used in a case-control study of asymptomatic colorectal adenomas, diet, and faecal characteristics now in progress in Nottingham. All the interviews were carried out by one of us (NJJ).

In the interview schedule, in order to facilitate the subject's recall, the methods of recording varied according to the type of food. The introductory sections were in part designed to orient the subjects to the topic. A sequence of questions was asked relating to foods likely to be used in the preparation of, or consumed during, a substantial number of meals, eg, butter, margarine, milk, bread. The family's weekly consumption of fats was recorded at the interview along with the number of adults and children in the family. Respondents were asked to think in terms of what they eat in a typical week in the main sections of the schedule. They were asked to describe what they would have for breakfast, what they would have for their main meals and their snacks and so forth. In order to convert the dietary information into estimated nutrient intakes, the basic calculation was weight per week times concentration (as estimated from the computerised McCance and Widdowson tables ${ }^{24}$ ). In order to facilitate coding, the methods of recording varied according to the type of food. The record was divided into a number of sections, for each of which there was a conversion routine from the recorded value to the weight in grams:

(1) Butter, margarine, cooking fat, milk, cream, cheese, sugar, eggs, bread, alcoholic drinks and soft drinks: the subject was asked to estimate the quantity consumed per week.

(2) Food items for which average portion size was assumed. 
(3) Food items whose intake was specified by number consumed, eg, certain fruits.

(4) Food items where portion size (small/ medium/large) was specified by the subject by inspecting photographs; in the case of vegetables, the weight estimate was adjusted for reported seasonal variation in consumption.

(5) Other foods, recorded directly in terms of the weight consumed per week.

In the absence of data on typical portion sizes in the United Kingdom, estimates were derived from a mixture of suggestions by dietitians (including the photographed items used when asking subjects about typical portion sizes consumed), the Ministry of Agriculture, Fisheries and Food ${ }^{25}$ and data from the United States. ${ }^{2627}$ As we were concerned about the possible risk of misclassification which can arise when people follow diets with varying proportions of food items for which portion sizes had been estimated from one source of data, we had these estimates reviewed and revised where necessary by the nutritionist working on the joint DHSS/MAFF survey of 2000 adults currently in progress. In the pilot stage of this survey, portion sizes had been obtained from food manufacturers.

One of the main considerations in designing the self completed questionnaire was the response rate. For this reason, the questionnaire was based on that developed by Yarnell et $a l^{9}$ to investigate the nutritional determinants of ischaemic heart disease. This questionnaire offered the advantages of brevity and ease of completion as compared to previous questionnaires used in the British Isles and America.

In designing the questionnaire, information on the main sources of the nutrients considered was obtained from a Department of Health and Social Security survey ${ }^{28}$ of the elderly. Sixty two food items or groups were considered. For each food item specified, the subject was asked to circle the number of times the food is eaten per week (1-7) or less frequently (less than once a week, more than once a month $=M$; rarely or never eaten $=R$ ). For example the entry below indicated that cornflakes were eaten five times per week

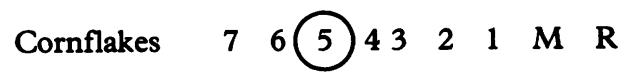

In contrast to the interview schedule in which the intake reported for the family was recorded, only the subject's weekly consumption of fats likely to be consumed in the preparation of, or consumed during, a substantial number of meals was recorded.

Processing of dietary data from the questionnaire involved conversion of frequencies with which food items were eaten to estimates of nutrient intake; portion sizes for foods for which variable portion sizes were considered in the interview data were taken as "medium".

Nutrient intakes were estimated from the two sets of data on consumption of specific foods using the computerised McCance and Widdowson tables. ${ }^{24}$

The distributions of nutrient intakes estimated from the interview and questionnaire were defined in terms of the range of estimated weekly intake. Tests of skewness and kurtosis were performed. Fat intake estimated from the questionnaire was non-normal, and could not be transformed to approximate to a normal distribution. Accordingly, while the mean intakes of fibre and calcium could be compared, and product moment correlation coefficients calculated with Fisher's z transformation used to determine $95 \%$ confidence intervals, nonparametric methods had to be used to analyse estimated fat intake. Ninety five per cent confidence intervals for the median and for Spearman's rank correlation coefficient were determined by the methods described by Campbell and Gardner ${ }^{29}$ and Altman and Gardner $^{30}$ respectively. Tertile ranking was compared using the weighted Kappa statistic with standard weights..$^{31}$ Approximate $95^{\circ} 0^{\circ}$ confidence intervals of Kappa were deteremined using the large sample normal approximation.

\section{Results}

Of the 130 eligible subjects, 84 originally agreed to take part. Three people from group 1 completed the questionnaire but refused to be interviewed. One person from group 2 decided to drop out before the interview. The remainder did not respond even after a reminder letter was sent. The overall response rate was therefore $615^{\circ}{ }_{1}{ }_{1}$. The response rate for the group who completed the questionnaire first and were interviewed later, henceforth referred to as group 1 , was $59 \cdot 1{ }^{\circ}$, and that for the group who were interviewed first, and completed the questionnaire later, henceforth referred to as group 2, was $64.1 \%$. The distributions of age, sex and marital status in the two groups were similar (table II).

The distributions of the nutrient intakes estimated from the interview data and from the
Table II Comparison of sociodemographic characteristics between group 1 and group 2

\begin{tabular}{|c|c|c|c|c|c|c|c|c|c|c|}
\hline & \multicolumn{5}{|c|}{ Group 1} & \multicolumn{5}{|c|}{ Group 2} \\
\hline & $\mathbf{n}$ & $\%$ & Range & Mean & (SD) & $\mathrm{n}$ & $0_{0}$ & Range & Mean & (SD) \\
\hline $\begin{array}{l}\text { Male } \\
\text { Female }\end{array}$ & $\begin{array}{l}20 \\
19\end{array}$ & $\begin{array}{l}51 \cdot 3 \\
46 \cdot 3\end{array}$ & & & & $\begin{array}{l}19 \\
22\end{array}$ & $\begin{array}{l}48 \cdot 7 \\
53 \cdot 7\end{array}$ & & & \\
\hline $\begin{array}{l}\text { Age (years) } \\
\text { Men } \\
\text { Women }\end{array}$ & & & $\begin{array}{l}65-74 \\
59-69\end{array}$ & $\begin{array}{l}69.5 \\
63.7\end{array}$ & $\begin{array}{l}(3 \cdot 1) \\
(2 \cdot 6)\end{array}$ & & & $\begin{array}{l}65-74 \\
59-67\end{array}$ & $\begin{array}{l}69 \cdot 2 \\
63 \cdot 5\end{array}$ & $\begin{array}{l}(2 \cdot 7) \\
(2 \cdot 4)\end{array}$ \\
\hline $\begin{array}{l}\text { Marital status } \\
\text { Married } \\
\text { Widowed }\end{array}$ & $\begin{array}{r}24 \\
5\end{array}$ & $\begin{array}{l}61.5 \\
12.8\end{array}$ & & & & $\begin{array}{r}29 \\
7\end{array}$ & $\begin{array}{l}70 \cdot 7 \\
17 \cdot 1\end{array}$ & & & \\
\hline $\begin{array}{l}\text { Divorced/ } \\
\text { separated } \\
\text { Single }\end{array}$ & $\begin{array}{l}3 \\
7\end{array}$ & $\begin{array}{r}7.7 \\
17.9\end{array}$ & & & & $\begin{array}{l}2 \\
3\end{array}$ & $\begin{array}{l}4.9 \\
7 \cdot 3\end{array}$ & & & \\
\hline
\end{tabular}


Table III Comparison of fibre, fat and calcium intake estimated from questionnaire data and from interview data

\begin{tabular}{|c|c|c|c|}
\hline \multirow[b]{2}{*}{ Variable } & \multicolumn{3}{|l|}{ Nutrient } \\
\hline & Fibre & Fat & Calcium \\
\hline \multicolumn{4}{|l|}{$\begin{array}{l}\text { Range of estimated weekly intakes } \\
(\mathrm{g}, \text { calcium } \mathrm{mg})\end{array}$} \\
\hline $\begin{array}{l}\text { Questionnaire } \\
\text { Interview }\end{array}$ & $\begin{array}{l}37 \cdot 1-324 \cdot 8 \\
37 \cdot 8-314 \cdot 1\end{array}$ & $\begin{array}{l}196 \cdot 5-1914 \cdot 8 \\
140 \cdot 2-1212 \cdot 4\end{array}$ & $\begin{array}{l}1254-8822 \\
1725-7371\end{array}$ \\
\hline \multicolumn{4}{|l|}{ Weekly intake $(95 \% \mathrm{CI})$} \\
\hline Type of estimate & Mean & Median & Mean \\
\hline $\begin{array}{l}\text { Questionnaire } \\
\text { Interview }\end{array}$ & $\begin{array}{ll}140 \cdot 5 & (126 \cdot 9-154 \cdot 1) \\
181 \cdot 1 & (167 \cdot 4-194 \cdot 8)\end{array}$ & $\begin{array}{ll}581.9 & (497 \cdot 4-642 \cdot 7) \\
573 \cdot 2 & (504 \cdot 4-618 \cdot 0)\end{array}$ & $\begin{array}{ll}4319 & (3968-4670) \\
4434 & (4148-4720)\end{array}$ \\
\hline \multicolumn{4}{|l|}{$\begin{array}{l}\text { Assignment to tertiles of intake } \\
\text { compared, } n(\%)\end{array}$} \\
\hline $\begin{array}{l}\text { Same } \\
\text { Adjacent } \\
\text { Opposite }\end{array}$ & $\begin{array}{rr}46 & (57.5) \\
26 & (32.5) \\
8 & (10.0)\end{array}$ & $\begin{aligned} 42 & (52.5) \\
29 & (36.3) \\
9 & (11 \cdot 3)\end{aligned}$ & $\begin{array}{rr}39 & (48.8) \\
34 & (42.5) \\
7 & (8.8)\end{array}$ \\
\hline Weighted Kappa (95\% CI) & $0.45 \quad(0.26-0.65)$ & $0.40 \quad(0.19-0.60)$ & $0.42 \quad(0.23-0.60)$ \\
\hline \multicolumn{4}{|l|}{$\begin{array}{l}\text { Correlation between estimated } \\
\text { intakes }\end{array}$} \\
\hline $\begin{array}{l}\text { Type } \\
\text { Coefficient }(95 \% \mathrm{CI})\end{array}$ & $\begin{array}{l}\text { Product moment } \\
0.49 \quad(0.31-0.64)\end{array}$ & $\begin{array}{l}\text { Spearman's rank } \\
0.45 \quad(0.26-0.61)\end{array}$ & $\begin{array}{l}\text { Product moment } \\
0.42 \quad(0.22-0.58)\end{array}$ \\
\hline
\end{tabular}

$\mathrm{CI}=$ confidence interval

questionnaire data are presented in table III. Both fibre and calcium intake as estimated by the two methods approximated to a normal distribution (the coefficients of skewness and kurtosis for fibre intake estimated by questionnaire were 0.84 and 0.51 respectively, and by interview were 0.08 and -0.35 respectively; the coefficients for calcium intake estimated by questionnaire were 0.95 and 0.79 respectively, and by interview 0.41 and -0.38 respectively). This was also true of fat intake estimated from the interview (the coefficient of kurtosis was $\mathbf{0 . 3 7}$ and of skewness 0.99). However, the distribution of fat intake estimated from the questionnaire showed considerable skewness (coefficient 2.09) and kurtosis (coefficient $7 \cdot 12$ ).

The ranges of estimated weekly intakes of fibre, fat and calcium were wider in the questionnaire than in the interview. However, the mean estimated weekly intakes of fibre and calcium were higher in the interview data. By contrast the median estimated weekly intake of fat was higher in the questionnaire data.

At $58 \%$ the agreement in tertile ranking was greatest for fibre, compared with $52.2 \%$ for fat and $49 \%$ for calcium (table III). The weighted Kappa coefficients were $0.45,0.40$ and 0.42 respectively. The product moment correlation coefficients of estimated intakes of fibre and calcium were 0.45 and 0.42 respectively, while the Spearman rank correlation coefficient of estimated fat intakes was $\mathbf{0 . 4 9}$.

Subjects in group 1 showed the greater percentage of concordance of tertile ranking (table IV). Only fat ranking showed a significant difference between groups 1 and 2 , and in whether or not the subject was placed in the same tertile $\left(\chi^{2} 6 \cdot 1\right.$, with $\left.1 \mathrm{df}, \mathrm{p}<0.025\right)$.

The extent of the differences in nutrient intake estimates between the two methods was found to be unaffected by categories of age, sex, marital status or smoking patters (table V).

\section{Discussion}

The overall response rate was low $(61.5 \%)$. However, the population consisted of elderly subjects resident in a deprived area who had little personal motivation to take part. A poor response rate in a deprived area is consistent with the finding that working class groups are less likely to respond to health surveys. ${ }^{32}$ The age distribution of non-responders was similar to that of responder, but the male proportion in nonresponders was higher (0.69 as compared to 0.49$)$. A plausible explanation is that women have more interest in participating in a study of this type, especially in this age group, because they are more likely to be the domestic partner in a marriage and would therefore be expected to be more aware of issues relating to diet. We noted a similar pattern when the group of responders were divided into those who required a reminder letter or not (male proportion 0.59 and 0.45 respectively).

Social class was not recorded in either the interview or questionnaire. Exton-Smith ${ }^{33}$ found that an increase in social deprivation occurs with advancing age. It is common practice in studies to take the last occupation before retirement to establish social status. However, this may

Table IV Comparison of tertile placing for questionnaire and interview data for groups 1 and 2

\begin{tabular}{|c|c|c|c|c|c|c|c|c|c|}
\hline \multirow[b]{2}{*}{ Nutrient } & \multicolumn{4}{|l|}{ Group 1} & \multicolumn{4}{|l|}{ Group 2} & \multirow{2}{*}{$\begin{array}{l}\text { Comparison of proportions } \\
\text { assigned to same } v \text { adjacent } \\
\text { or opposite tertiles between } \\
\text { group } 1 \text { and group } 2, \chi_{1}^{2}\end{array}$} \\
\hline & $\begin{array}{l}\text { Same } \\
\text { n }(\%)\end{array}$ & $\begin{array}{l}\text { Adjacent } \\
\text { n }(\%)\end{array}$ & $\begin{array}{l}\text { Opposite } \\
\text { n }(\%)\end{array}$ & $\begin{array}{l}\text { Weighted Kappa } \\
(95 \% \text { CI })\end{array}$ & $\begin{array}{l}\text { Same } \\
\text { n }(\%)\end{array}$ & $\begin{array}{l}\text { Adjacent } \\
\left.\text { n ( }{ }^{0}{ }_{0}\right)\end{array}$ & $\begin{array}{l}\text { Opposite } \\
\text { n }\left({ }_{0}^{0}\right)\end{array}$ & $\begin{array}{l}\text { Weighted Kappa } \\
\left(95^{\circ}{ }_{0} \mathrm{CI}\right)\end{array}$ & \\
\hline Fibre & $23(59.0)$ & $12(30 \cdot 8)$ & $4(10 \cdot 3)$ & $0.58(0.32-0.83)$ & $23(56 \cdot 1)$ & $14(34 \cdot 1)$ & $4(9 \cdot 8)$ & $0.44(0 \cdot 17-0.72)$ & $0.1 p>0.7$ \\
\hline Fat & $26(66 \cdot 7)$ & $11(28 \cdot 2)$ & $2(5 \cdot 1)$ & $0.58(0.36-0.80)$ & $16(39 \cdot 0)$ & $18(43.9)$ & $7(17 \cdot 1)$ & $0.28(0.01-0.56)$ & $6.10 .05>p>0.025$ \\
\hline Calcium & $21(53.8)$ & $14(35.9)$ & $4(10 \cdot 3)$ & $0.39(0.11-0.66)$ & $18(43.9)$ & $20(48 \cdot 8)$ & $3(17 \cdot 3)$ & $0.48(0.24-0.72)$ & $0.4 p>0.5$ \\
\hline
\end{tabular}

$\mathrm{CI}=$ confidence interval 
Table $V$ Differences in estimated nutrient intakes by sociodemographic characteristics

Median ${ }^{\star}\left(95^{\circ} \circ \mathrm{CI}\right)$ difference (interview value -questionnaire value) in intake

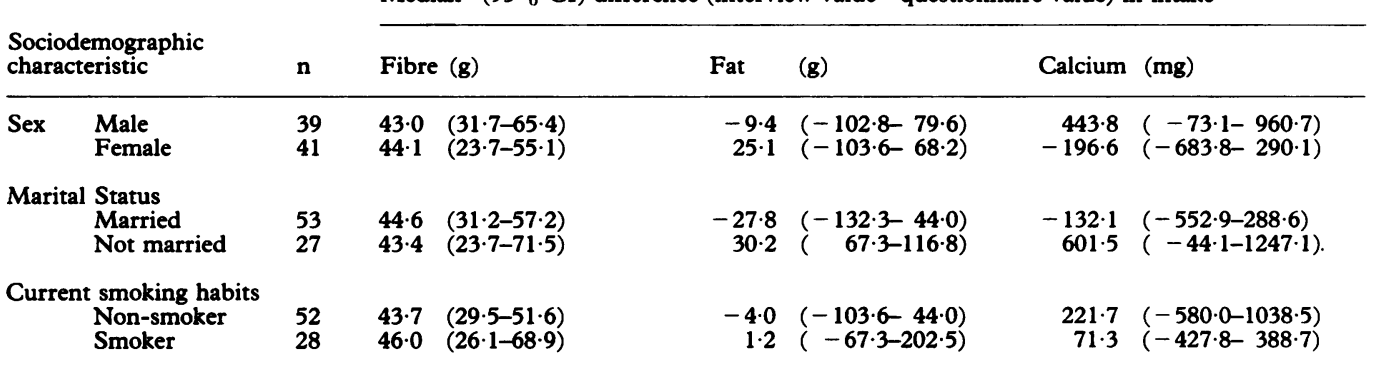

* For calcium intake by sex and marital status, mean differences were assessed.

$\mathrm{CI}=$ confidence interval

introduce the "healthy worker" effect whereby a degradation in health results in a decrease in the job status. To prevent this, a detailed job history would be required which would have considerably increased the length of the interview. However, as all the subjects were elderly, and the main catchment area of the health centre comprised areas classified as of "extreme" or "serious" disadvantage according to a scoring system based on indicators of poverty, unemployment, social class, housing, health and family problems, ${ }^{18}$ it seems reasonable to assume that the social class status was similar throughout the study group. Seventeen married couples were included in the study, eight in group 1 and nine in group 2. The inclusion of married couples raised problems in the administration of the questionnaire and interview. For both group 1 and 2 , the importance of completing the questionnaires separately was stressed. Nevertheless, the possibility cannot be excluded that some conferring took place. Interviews were carried out with both partners present. Although questions were asked separately to each spouse, the possibility that the responses of each influenced the other cannot be ruled out.

The questionnaire included 62 food items or groups. The interview, not surprisingly, could record many more food items. To simplify the questionnaire, foods which contained similar amounts of fibre, fat and calcium were grouped together as one item, eg, green vegetables. The results of this may have been to overgeneralise the questionnaire and therefore decrease its sensitivity. Sauces and jams, etc, were not included in the questionnaire. Foods thought to be consumed rarely were also not included (eg, faggots, tripe, rabbit). Such foods only became apparent as a major constituent of the diet for some subjects after the interviews had been conducted.

The possible number of responses for frequencies with which foods were eaten differed in the interview and questionnaire. The questionnaire responses allowed for the exact number of times a week a particular food or group of foods were eaten. The interview, on the other hand, grouped frequencies together, eg, 2-3 times a week, 4-5 times a week, etc. The overall intakes of nutrients were calculated as weekly consumptions. It is therefore possible that the differences in responses available may have contributed to the discrepancy between the intakes estimated by the interview and the questionnaire.
Some studies have shown marked seasonal variations for some nutrients. McKeown-Eyssen et al $^{34}$ noted that the results of many repeatability studies were difficult to interpret because the data on which the estimates were obtained were collected during two different times of the year. The maximum interval between the two methods in this study was approximately six weeks and therefore dietary intake is likely to have remained constant.

Neither technique used in the present study provides an exact estimate of intake. In particular, both techniques are open to the criticism that current diet may influence recall of past diet, ${ }^{35-40}$ thereby leading to potential recall bias in casecontrol studies. Studies based on interviews offer the advantage of the opportunity for probing, thereby enabling intakes of foods eaten infrequently to be assessed, and the complementary disadvantage that they are open to bias on the part of interviewers if they are not "blind" to the status of the respondent. By contrast, subjects in studies based on self completed questionnaires may have difficulty in estimating frequencies of consumption, and the range of foods considered has to be limited. It therefore does not appear surprising that many studies have shown that diet history interviews yield higher estimates of nutrient intake than other methods. ${ }^{41-49}$ In theory, interview based studies enable variations in diet during the subjects lifetime to be assessed, although reports vary in the extent to which they suggest that the data are a reflection of current diet. ${ }^{35} 37394050$ In view of these caveats, it is reassuring that both techniques provided estimates of intakes similar to those of other studies.

Little comparable information on mean intake of fibre in the United Kingdom is available. A weekly intake of $149.8 \mathrm{~g}(7 \times 21.4)$ was estimated in the 1986 Household Food Consumption and Expenditure Survey. ${ }^{51}$ Using a food frequency approach, Yarnell et $a l^{9}$ estimated a mean weekly intake of $128.1 \mathrm{~g}$, while Bristol et al, ${ }^{52}$ in their case-control study of colorectal cancer and diet assessed by diet history interview, found a weekly intake of $136.5 \mathrm{~g}$ in their control group. In subjects aged 35-54, resident in Ipswich, Stoke and Wakefield, weekly intakes as assessed by 24 hour diary were in the range $123.9-144.9 \mathrm{~g} .{ }^{53}$ The estimates from the present study, therefore, are of a similar order to those of other studies.

Estimates of both fat and calcium are of a similar order, but somewhat lower than those reported for persons in households in which the 
housewife was aged 65-74 in the 1984 Household Food Consumption and Expenditure Survey, ${ }^{54}$ the most recent year in which a breakdown is available by age. The differences reflect the fact that the Household Survey is of household food purchases rather than of individual consumption. Little information is available on the diets of individuals in the United Kingdom. ${ }^{55}$ The intake of fat was higher than that estimated for the control group in the study of Bristol et al, ${ }^{52}$ but it should be noted that the majority of control subjects were obtained from orthopaedic outpatient and fracture clinics, so their total intake would be expected to be lower than that of the healthy general population. Yarnell et al, ${ }^{9}$ using a questionnaire similar to that used in the present study, found a slightly lower weekly fat intake, $557 \mathrm{~g}$ compared with $580 \mathrm{~g}$ in the present study. Fat intakes in our study lay within the range reported for men and women by Bingham $e t$ $a l^{55}$ and by Cade et al. ${ }^{53}$ Cummings et $a l^{56}$ assessed calcium intake in elderly women and found similar, although slightly higher, estimates: $4560-4816 \mathrm{mg}$ compared with $4319-4434 \mathrm{mg}$ from the present study. Again, Bingham et $a p^{55}$ estimated higher calcium intakes $(6818 \mathrm{mg} /$ week in seven men; $5075 \mathrm{mg} /$ week in seven women) in weighed dietary records from subjects aged 60-79.

Lower estimates were obtained for the mean weekday intakes of fibre and calcium as measured by the questionnaire compared with the diet history. This finding is consistent with studies in which food frequency and diet history data have been compared, and with other studies in which estimates of nutrient intakes based on diet histories were compared to those obtained from other methods. ${ }^{41} 43-46$ By contrast, the median weekly fat intake estimated from the questionnaire data was higher than that estimated from the diet history data.

Both fibre and calcium intake estimated by the two methods approximated to a normal distribution. This was also true of fat estimated by the interview. However, fat estimated by the questionnaire showed considerable skewness and kurtosis in its distribution. Significant differences were found between butter, margarine and cream consumption estimated by the interview and questionnaire. It was thought that the discrepancy was due, in part, to some subjects estimating their family's consumption rather than their personal consumption in the questionnaire. Another factor contributing to the discrepancy is the recording of how a particular food was cooked. Unlike the interview, where grilled or fried food can be specified, the questionnaire assumes certain foods to be fried, for example, beefburgers and sausages.

In case-control studies of chronic diseases it is more important to be able to rank individuals reliably in the population according to their nutrient intake over a prolonged period rather than to obtain a precise estimate of their absolute nutrient intakes at one particular time. In many studies, the reliability of different methods of dietary inquiry has been assessed by correlation analysis, but the usual test of significance of a correlation coefficient, that it is significantly different from zero, is inappropriate, as the null hypothesis should be that the coefficient is unity. ${ }^{57}$ We have therefore focused initially on tertile ranking.

The agreement in tertile ranking was $58^{\circ}{ }_{0}$ for fibre, $53 \%$ for fat and $49^{\circ}$ o for calcium, figures not dissimilar to other studies, ${ }^{94758}$ with weighted Kappa coefficients of $0.45,0.40$ and 0.42 respectively (table III) again in line with previous studies. ${ }^{9245-4749566061}$ The corresponding correlation coefficients for estimated nutrient intakes were $0.49,0.45$ and 0.41 respectively. The similarity of the weighted Kappa and correlation coefficients for estimated fibre and calcium intakes reflects the fact that use of standard weights makes weighted Kappa equivalent to the intraclass correlation coefficient. ${ }^{62}$ The absolute estimates of nutrient intake were similar to those in the most closely comparable studies. 956

Group 1 subjects received a copy of the questionnaire prior to the interview. Subjects in group 2 received a copy of the questionnaire after the interview. As the time interval between the two methods was greater for group 1 (3-6 weeks compared with 4-6 days) it would be expected that the difference between the nutrient intakes would be smaller for group 2. Comparison between interview and questionnaire tertile ranking of the nutrients, showed a greater percentage of concordance for group 1 . However, this was only significant for fat. It was thought this was because subjects in group 2 completed the questionnaire having retained the memory of recording the family's consumption of fats during the interview, and this led to an overestimation of fat consumption in the questionnaire.

No significant relationships were found between age, sex, marital status or smoking and the extent of the differences in nutrient intakes estimated by the two methods. Similar results were found by Colditz et $a l^{63}$ and Thompson et $a l^{64}$ Thompson et al also found reproducibility to be lower for subjects who reported health problems. No relationship was found in this study between the extent of the differences in nutrient estimates between the two methods and various health problems (varicose veins, constipation, haemorrhoids), but numbers were small. In future studies, it would be relevant to obtain data on the effect of obesity (body mass index) on the differences in ranking of subjects by nutrient intake as estimated by the two methods, particularly in view of the concern about the potential confounding effect of total energy intake. ${ }^{165}$

So far, the reasons for the discrepancy between the two methods have been considered as attributable to the methods themselves. Little attention has been given to the degree of validity of the subjects' responses. Subjects were asked in both the interview and the questionnaire whether they had changed the quantity of intake in the previous year. In the interview, they were asked the question both in general and specifically for fibre (roughage), fat and sugar. In the questionnaire, a similar approach was used, the only difference being that the question on fat was split into "dairy products" and "fatty foods in general". Few subjects responded in any way to the specific questions in the questionnaire 
whereas in the interview, 29 subjects stated that they had increased their fibre intake, two that they had reduced it, 33 subjects stated that they had reduced their fat intake, three that they had increased it, and 14 subjects stated that they had reduced their sugar intake, two that they had increased it. Regarding overall change in intake, $71.3 \%$ of subjects placed themselves in the same category (weighted Kappa $=0.49$; $95 \%$ confidence interval $0 \cdot 26-0 \cdot 71)$. Although we are concerned about the level of disagreement $(28.7 \%)$ on the general question, we believe that this reflects more the inadequacy of the approach used to assess changes applying in different directions to different foods or nutrients, especially in the questionnaire, than the reliability of the results relating to estimated nutrient intakes.

Lee et al $^{66}$ have commented that as the true diet of subjects living in the community cannot be ascertained with absolute accuracy, the aim of validation studies has become the determination of whether one method is interchangeable with a method of greater acceptance or one that has greater face validity. These authors also noted that the association between nutrient intake and cancer in case-control studies has often been measured by the mean difference in nutrient intake between cases and controls. In such a situation, two dietary methods are interchangeable only if the linear regression coefficient of the intake estimated from the method under test on the intake estimated from the reference method is equal to 1.0 . In the present study, the interview method was the less accepted of the two, so we sought to determine the regression coefficients for intakes estimated from the interview on intakes estimated from the questionnaire. We were unable to transform the distribution of fat intake as estimated by the questionnaire to a normal distribution, so the assumptions of the regression method could not be satisfied for this variable. The regression coefficient for fibre was 0.49 (95\% confidence interval $\left.0.30-0.69 ; r^{2}=0.24\right)$ and for calcium it was $0.34(95 \%$ confidence interval $0 \cdot 18-0.50$; $\left.r^{2}=0 \cdot 17\right)$. These results suggest that the methods will not provide the same result if the objective is to compare mean differences between cases and controls. However, in more recent studies, interest has focused on the ranking of subjects in terms of their intake with a view to identifying possible dose-response associations. One major difference between the questionnaire and the interview was that, in the latter, variation in habitual portion sizes between subjects could be assessed. Many authors are still uncertain of the importance of portion size in the assessment of dietary intake. The data from the interview were reanalysed taking the portion size as medium for all foods. The values were then compared with the questionnaire data. Surprisingly, for fat and calcium the percentage of exact agreement in tertile ranking decreased from $52.2 \%$ to $47.5 \%$ and from $48.8 \%$ to $45.0 \%$ respectively, as did the correlation coefficients (fat: Spearman's rank correlation coefficient decreased from 0.45 to 0.30 ; calcium: product moment correlation coefficient decreased from 0.42 to 0.33 ). By contrast, the degree of agreement in estimated fibre intake between the methods increased, with five subjects being reclassified as belonging to adjacent rather than opposite tertiles, but there were no other changes in ranking (the product moment correlation coefficient increased from 0.49 to 0.51 ). Therefore the degree of reliance that can be placed on this result is uncertain since the changes in concordance of tertile ranking may be due to a few subjects influencing the results of the small sample. The estimated mean intakes of fibre and calcium and the estimated median fat intake all decreased. This decrease in values is consistent with previous studies in that an index based on frequency alone has the lowest value and increases significantly when amount is combined with frequency. 4 7-4956

As the results were similar to those of other studies, and gross misclassification was low, we conclude that the dietary interview used in the present study is of a similar reliability to those used in other studies for subjects in the general population. The issue of reliability will be investigated further in the analysis of repeat interviews of samples of subjects with colorectal adenomatous polyps and their controls. While a method was used as the reference method in the present study, further work is needed to determine whether it is an adequate substitute for the more labour-intensive diet history interview. This could be assessed by applying the two approaches to a cohort of subjects from whom dietary data had been collected at more than one stage.

The authors thank the subjects who participated in the study, the staff of Radford Health Centre for their help in the initial stages of the project, Mary Stevenson and Ian Turner for their help with data processing, and Claire Pegg and Janice Gillard for preparing the manuscript.

This work was carried out as part of a B Med Sci thesis in the Department of Community Medicine and Epidemiology, University of Nottingham Medical School.

1 Lyon JL, Gardner JW, West DW, Mahoney AM. Methodological issues in epidemiological studies of diet and cancer. Cancer Res 1983; (Suppl) 43: 2392-6s.

2 Bingham SA. The dietary assessment of individuals; methods, accuracy, new techniques and recommendations methods, accuracy, new techniques and recon
Nutr Abst Rev (Ser A) 1987; 57: 705-42.

3 Fehily AM. Epidemiology for nutrionists: 4. Survey Fehily AM. Epidemiology for nutrionists: 4. S
methods. Hum Nutr Appl Nutr 1983; 37A: 419-25.

4 Russel-Briefel R, Caggiula AW, Kuller LH. A comparison of three dietary methods for estimating vitamin $\mathrm{A}$ intake. Am $\mathcal{F}$ Epidemiological 1985; 122: 628-36.

5 Laker M. On determining trace element levels in man: the uses of blood and hair. Lancet 1982; ii: 260-2.

6 Van Staveren WA, Deurenberg P, Katan MB, Burema J, De Groot LCPGM, Hoffmans MDAF. Validity of the fatty acid composition of subcutaneous fat tissue microbiopsies as an estimate of the long-term average fatty acid composition of the diet of separate individuals. $A m \mathcal{J}$ Epidemiol 1986; 123: 455-63.

7 Hardcastle JD, Arrnitage NC, Chamberlain J, Amar SS, James PD, Balfour TW. Fecal occult blood screening for colorectal cancer in the general population: results of a controlled trial. Cancer 1986; 58: 397-403.

8 Pequignot G, Cubeau J. Enquêtes méthodologiques comparant chez les mêmes sujets la consommation alimentaire appréciée par interrogatoire à la consommation mesuree

9 Yarnell JWG, Fehily AM, Milbank JE, Sweetnam PM, Walker CL. A short dietary questionnaire for use in epidemiological surveys: comparison with weighed dietary epidemiological surveys: comparison with weighed
records. Hum Nutr Appl Nutr 1983; 37A: 103-12.

10 Boyle P, Zaridze DG, Smans M. Descriptive epidemiology Boyle $P$, Zaridze DG, Smans M. Descriptive epidem
of colorectal cancer. Int $\mathcal{Y}$ Cancer 1985; 36: 9-18.

11 Kolonel LN. Fat and colon cancer: how firm is the Kolonel LN. Fat and colon cancer: how firm is the
epidemiologic evidence? Am $\mathcal{F}$ Clin Nutr 1987; 45: 336-41. 12 Byers T. Diet and cancer. Any progress in the interim?
Cancer 1988; 62: 1713-24. 
13 Newmark HL, Wargovich MJ, Bruce WR. Colon cancer and dietary fat, phospate, and calcium: a hypothesis. $\mathcal{f}$ Nat dietary fat, phospate, and cal
Cancer Inst 1984; 72: 1323-5.

14 Wu AH, Paganini-Hill A, Ross RK, Henderson BE. Alcohol, physical activity and other risk factors for colorectal cancer: a prospective study. $B r f$ Cancer 1987 ; 55 687-94.

15 Sorenson AW, Slattery ML, Ford MH. Calcium and colon cancer: a review. Nutr Cancer 1988; 11: 135-45.

16 Hunt R. Questionnaires. In: The dietary assessment of populations. Southampton: MRC Environmental Epidemiology Unit Scientific Report No 4, 1984: 9-13.

17 Block G. A review of validations of dietary assessment methods. Am $₹$ Epidemiology 1982; 115: 492-505.

18 Nottinghamshire County Council. Disadvantage in Nottinghamshire: County Deprived Area Study, Part 1. Nottinghamshire County Council, 1983: 10-17.

19 Whitehead M. The health divide: inequalities in health in the 1980's. London: Health Education Council, 1987.

20 Townsend P, Phillimore P, Beattie A. Health and deprivation: inequality and the North. London: Croom deprivation:

21 Nicoll A, Bassett $K$, Ulijaszek SJ. What's in a name? Accuracy in using surnames and forenames in ascribing Asian ethnic identity in English populations. $\mathcal{f}$ Epidemio Community Health 1986; 40: 364-8.

22 Marmot MG, Adelstein AM, Bulusu L. Lessons from the study of immigrant mortality. Lancet 1984; i: 1455-7.

23 Mather H, Keen H. The Southall Diabetes Survey: prevalence of known diabetes in Asians and Europeans. $B$ Med F 1985; 291: 1081-4.

24 Paul AA, Southgate DAT . McCance and Widdowson's The Composition of Foods'. 4th ed. London: HMSO, 1978.

25 Ministry of Agriculture, Fisheries and Food. Household food consumption and expenditure 1983. London: HMSO, 1985.

26 Adams CF. Nutrive value of American foods in common units. Washington DC: US Department of Agriculture, 1975.

27 Church CF, Church HN. Food values of portions commonly used. 12th ed. Philadelphia: JB Lippincott, 1975.

28 Department of Health and Social Security. $A$ Nutrition Department of Health and Social Security. A Nutrition
survey of the elderly. Report on Health and Social Subjects survey of the elderly. Report on
No 3. London: HMSO, 1972.

29 Campbell MJ, Gardner MJ. Calculating confidence intervals for some non-parametric analyses. $\mathrm{Br} \mathrm{Med} \mathcal{F} 1988$ 296: $1454-6$.

30 Altman DG, Gardner MJ. Calculating confidence intervals for regression and correlation. $\mathrm{Br} M e d \mathcal{f} 1988 ; 296$ $1238-42$.

31 Maclure M, Willett WC. Misinterpretation and misuse of the Kappa statistic. Am $\mathcal{f}$ Epidemiol 1987; 126: 161-9.

32 Quigley C, Williams J. The Stockport Health Survey. Stockport Health Authority, 1988.

33 Exton-Smith AN. Epidemiological studies in the elderly: methodological considerations. Am f Clin Nutr 1982; 35: 1273-9.

34 McKeown-Eyssen GE, Yeung KS, Bright-See E. Assessment of past diet in epidemiologic studies. $\mathrm{Am} \mathcal{F}$ Epidemiol 1986; 124: 94-103.

35 Garland B, Ibrahim M, Grimson R. Assessment of past diet in cancer epidemiology (abstract). Am $¥$ Epidemiol 1982; 166: 577 .

36 Byers TE, Rosenthal RI, Marshall JR, Rzepka TF, Cummings $M$, Graham $S$. Dietary history from the distant past: a methodological study. Nutr Cancer 1983; .5: 69-77.

37 Jensen OM, Wahrendorf J, Rosenquist A, Geser A. The reliability of questionnaire-derived historical dietary information and temporal stability of food habits in individuals. Am F Epidemiol 1984; 120: 281-90.

38 Van Staveren WA, West CE, Hoffmans MDAF et al. Comparison of contemporaneous and retrospective estimates of food consumption made by a dietary history method. Am $\mathcal{F}$ Epidemiol 1986; 123: 884-93.

39 Byers T, Marshall J, Anthony E, Fielder R, Zielenzy M. The reliability of diet history from the distant past. $\mathrm{Am} \mathcal{F}$ Epidemiol 1987; 125: 999-1011.

40 Thompson FE, Lamphiear DE, Metzner HL, Hawthorne VM, Oh MS. Reproducibility of reports of frequency of food use in the Tecumseh diet methodology study. $A m \mathcal{F}$ Epidemiol 1987; 125: 658-71.
41 Young CM, Chalmers RW, Church HN, et al. A comparison of dietary study methods; dietary history vs 7 -day record. $\tilde{F}$ Am Diet Assoc 1952; 28: 124-8.

42 Browe JH, Gofstein RM, Morley DM, McCarthy MC. Diet and heart disease study in the CVS health centre. $f \mathrm{Am} \mathrm{Diet}$ Assoc 1966; 48: 95-108.

43 Paul O, Lepper MH, Phelan WH, et al. A longitudinal study of coronary heart disease. Circulation 1963; 28: 20-3.

44 Hartog C den, Schaik TF van, Dalderup LM, et al. The die of volunteers participating in a long term epidemiological field survey on coronary heart disease at Zutphen, the Netherlands. Voeding 1965; 26: 184-208.

45 Morgan RW, Jain M, Miller AB, et al. Comparison of dietary methods in epidemiological studies. Am $\mathcal{F}$ Epidemiol dietary methods in

46 Jain M, Howe GR, Johnson KG, Miller AB. Evaluation of a diet history questionnaire for epidemiological studies. $A m \mathfrak{f}$ Epidemiol 1980; 111: 212-9.

47 Samet JM, Humble CG, Skipper BE. Alternatives in the collection and analysis of food frequency interview data. Am $\mathcal{F}$ Epidemiol 1984; 120: 572-81.

48 Lee J, Kolonel LN, Hankin JH. Cholesterol intake as measured by unquantified and quantified food frequency interviews: implications for epidemiol research. Int $f$ interviews: implications for

49 Wu ML, Whittemore AS, Jung DL. Errors in reported dietary intakes. Short term recall. Am $\mathcal{F}$ Epidemiol 1986 124: 826-35.

50 Wu ML, Whittemore AS, Jung DL. Errors in reported dietary intakes II. Long-term recall. Am $\mathcal{F}$ Epidemiol 1988 128: $1137-45$.

51 Ministry of Agriculture, Fisheries and Food. Household food consumption and expenditure 1986. London: HMSO, 1987.

52 Bristol JB, Emmett PM, Heaton KW, Williamson RCN. Sugar, fat and the risk of colorectal cancer. $\mathrm{Br} \mathrm{Med} \mathcal{F} 1985$; 291: $1467-70$

53 Cade JE, Barker DJP, Margetts BM, Morris JA. Diet and inequalities in health in three English towns. $\mathrm{Br}$ Med $\mathcal{f}$ 1988; 296: 1359-62.

54 Ministry of Agriculture, Fisheries and Food. Household food consumption and expenditure 1984. London: HMSO, 1986

55 Bingham S, McNeil NI, Cummings JH. The diet of individuals: a study of randomly-chosen cross-section of British adults in a Cambridgeshire village. Br $\mathcal{F}$ Nutr 1981 45: 23-35.

56 Cummings SR, Block G, McHenry K, Baron RB Evaluation of two food frequency methods of measurin dietary calcium intake. $A m \mathcal{F}$ Epidemiol 1987; 126: 796-802.

57 Altman DG. Statistics and ethics in medical research. V-analysing data. $B r$ Med F 1980; 281: 1473-5.

58 Huenemann RL, Turner D. Methods of dietary investigation. $\mathcal{F}$ Am Diet Assoc 1942; 18: 562-8.

59 Humble CG, Samet JM, Skipper BE. Use of quantified and frequency indices of vitamin $A$ intake in a case-contro study of lung cancer. Int $₹$ Epidemiol 1987; 16: 341-6.

60 Balogh M, Medalie JH, Smith H, et al. The development of a dietary questionnaire for an ischaemic heart disease survey. dietary questionnaire for an ischaem $\mathrm{M}$ Is $\mathrm{Sci}$ 1968; 4: 195-203.

61 Block G, Hartman AM, Dresser CM, Carroll MC, Gannon J, Gardner L. A data-based approach to diet questionnaire design and testing. Am $\mathcal{\text { I Epidemiol }} 1986 ; 124: 453-69$.

62 Fleiss JL, Cohen J. The equivalence of weighted Kappa and Fleiss JL, Cohen J. The equivalence of weighted Kappa and reliability. Educ Psychol Meas 1973; 33: 613-9.

63 Colditz GA, Willett WC, Stampfer MJ, et al. The influence of age, relative weight, smoking and alcohol intake on the reproducibility of a dietary questionnaire. Int $\mathcal{f}$ Epidemio 1987; 16: 392-8.

64 Thompson F, Lamphiear D, Matzner H, Archer M, Hawthorne V. Reproducibility of retrospective dietary reports (abstract). Am $\mathcal{F}$ Epidemiol 1984; 120: 464.

65 Willett W, Stampfer MJ. Total energy intake: implications for epidemiologic analyses. Am $\mathcal{f}$ Epidemiol 1986; 134: 17-27.

66 Lee J, Kolonel LN, Hankin JH. On establishing the interchangeability of different dietary-intake assessment methods used in studies of diet and cancer. Nutr Cancer 1983; 5: 215-8. 